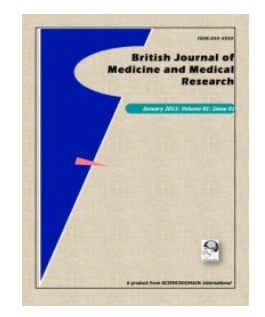

British Journal of Medicine \& Medical Research

3(3): 583-588, 2013

SCIENCEDOMAIN international

www.sciencedomain.org

\title{
Menstrual Cycle Disturbances in Diabetic Women in Kinshasa, DRC
}

\author{
Tandu-Umba Barthélémy ${ }^{{ }^{*}}$, Matondo Ponte Myphie-Patricia ${ }^{1}$ \\ and Mbangama Muela Andy ${ }^{1}$ \\ ${ }^{1}$ Department of Obstetrics and Gynecology, University Clinics Kinshasa, DR Congo.
}

\begin{abstract}
Authors' contributions
This work was carried out in collaboration between all authors. Author TUB generated the scientific ideas, study design, contributed to results interpretation and revised the manuscript critically. Author MPMP participated in the data collection and analysis. MMA participated in the data collection and data analyses. Authors TUB, MPMP and MMA certify to have read and approved the manuscript.
\end{abstract}

Research Article

Received $13^{\text {th }}$ November 2012

Accepted $29^{\text {th }}$ January 2013

Published $27^{\text {th }}$ February 2013

\section{ABSTRACT}

Objectives: This paper is intended to describe 1) the level of diabetes control and 2) related disturbances of the menstrual cycle among diabetic women in Kinshasa.

Study Design: It is a prospective, observational, case control study carried out from $1^{\text {st }}$ till $31^{\text {st }}$ July 2012 in a medical centre of Salvation Army, in Kinshasa, DR Congo, mostly giving low cost diabetic healthcare. Post menarche, non pregnant and non lactating diabetic women aged from 15 years up to 35 years attending a routine monthly visit were consecutively recruited after consent. The controls were enrolled consecutively after each case among non diabetic women. Fasting plasma glucose for patients and random plasma glucose values for controls were measured. Gynecologic antecedents including menstrual irregularities were recorded.

Statistical Analysis: Mean values are presented with standard deviations. Chi-square and student's t-test were used for comparison of characteristics' proportions and means of patients and controls. Odds ratio was used to seek for influence of diabetes on disturbances. Results are given with $95 \%$ confidence interval $(\mathrm{Cl})$, and $p<0.05$ as significant.

Results: During the period of study 35 patients and 35 controls were recruited. The mean glucose blood concentration of patients $(232.5 \pm 4.8 \mathrm{mg} / \mathrm{dL}$ vs $82.7 \pm 15.6 \mathrm{mg} / \mathrm{dL})$ is a 
marker of overall poor diabetes control. Late menarche was significantly more frequent in cases than in controls $(p=0.01 ; C l=8.5-48)$. As of menstrual troubles, differences appeared for amenorrhea $(p=0.000 ; C l=23.3-62.5)$ and spaniomenorrhea $(p=0.03$; $\mathrm{Cl}=2.4-43.3$ ), more frequent among patients.

Conclusions: Mean blood glucose concentration of diabetic women of the study averages $232.5 \mathrm{mg} / \mathrm{dL}$. Amenorrhea and spaniomenorrhea that characterize cycle disturbances in these patients could thus be regarded as need for better control of the illness and good contraception. Such a suboptimal diabetes management is expected to increase the burden of the illness not only in terms of chronic complications but also in reproductive health of the community.

Keywords: Menstrual cycle; disturbances; diabetic women; Congo.

\section{INTRODUCTION}

Delayed menarche [1-4], irregular menstrual cycles, lengthening of the menstrual cycle [2,3] and earlier menopause [5] are main disturbances of cycle that have been reported in diabetic women. They are caused by hyperglycemia that induces failure of the $\mathrm{GnRH}$ pulse generator [1]. This result in impairment of steroidogenesis, which, combined with insulin resistance or impaired insulin secretion or both is likely to decrease fertility. The prevalence of these disturbances appears to be greatly related to the quality of metabolic control as reflected by $\mathrm{HbA} 1 \mathrm{c}$ and insulin dose [2,3]. In developed countries attention is actively paid on these abnormalities which fortunately can be minimized (i.e. not completely reversed) by mean of adequate metabolic management of diabetes [1-3]. Nothing however has been reported concerning this issue in African countries where diabetes is getting epidemics while access to care remains questionable $[6,7]$.

This paper is intended to describe 1) the level of diabetes control and 2) related disturbances of the menstrual cycle among diabetic patients in Kinshasa in order to promote relevant management of this part of our female population.

\section{MATERIALS AND METHODS / EXPERIMENTAL DETAILS / METHODOLOGY}

This study was approved by the scientific board of the faculty of medicine (University of Kinshasa). It is a prospective, observational, case control study carried out from $1^{\text {st }}$ till July $31^{\text {st }}, 2012$ in a great medical centre of Salvation Army, in Kinshasa, DR Congo. The centre is one of those affiliated to the National Diabetes Program and provides low cost healthcare to patients with diabetes. Due to cost of dosages there is no use of haemoglobin A1c value to indicate glucose control status. Counselling and medical treatment are provided based on fasting plasma glucose concentration, the only laboratory measurement that is monthly recorded in medical charts of diabetic attendee's.

The study group was recruited after consent among consecutive non pregnant and non lactating diabetic women who attended the centre for their routine monthly visit. We restricted age from 15 years (supposed after menarche) up to 35 years (to avoid including peri-menopause related symptoms). In order to put forth impact of the illness on menstrual cycles we addressed the duration of diabetes as $\geq 3$ years or less. 
The control group was enrolled consecutively after each case among $15-35$ years supposed non diabetic women accompanying patients to the hospital. To make sure that controls were not ignored diabetic a random venous glucose was obtained from them by use of One touch profile meters (Lifescan, Johnson \& Johnson, High Wycombe, U.K.). General characteristics studied were: age, age at menarche, duration of menstruations, marital status, parity, gravidity, habitual abortion (one of typical findings in diabetic women). Clinical variables included body mass index (BMI) and menstrual cycle disturbances, namely: late menarche (age at menarche $>14$ years), intermenstrual syndrome, premenstrual syndrome, dysmenorrhea, amenorrhea, oligomenorrhea, spaniomenorrhea, pollakimenorrhea, polymenorrhea, anisomenorrhea, hypomenorrhea, hypermenorrhea, menorragia and menometrorragia.

\subsection{Statistical Analysis}

Mean values are presented with standard deviations and comparison between cases and controls was made using student's t-test. Chi-square was used for comparing proportions. Odds ratios were calculated to seek for influence of diabetes on occurrence of anomalies of the cycle. Results are given with $95 \%$ confidence interval $(\mathrm{Cl})$, and p .05 as significant.

\section{RESULTS AND DISCUSSION}

\subsection{Results}

During the period of study 35 diabetic women patients fulfilled the requirements and were recruited, all of them with type 1 diabetes. For $25(71.4 \%)$ of them the duration of diabetes was $\geq 3$ years and all were treated with ordinary rapid-acting and/or standard intermediateacting insulin (isophane insulin). Mean glucose blood concentration of patients (232.5 \pm $4.8 \mathrm{mg} / \mathrm{dL}$ ), not far from monthly values previously recorded in individual medical charts, was considered as a marker of poor glycemic control. Cases and controls were all post menarche. Based on random glucose blood concentration none of controls qualified as diabetic and their average blood glucose concentration was $82.7 \pm 15.6 \mathrm{mg} / \mathrm{dL}$.

Table 1 represents general characteristics of women studied. Controls were significantly older than cases.

Table 1. General characteristics of patients $(n=35)$ and controls $(n=35)$

\begin{tabular}{|c|c|c|c|c|c|c|}
\hline Variables & Diabetics & $\begin{array}{l}\text { Non } \\
\text { diabetics }\end{array}$ & $\begin{array}{l}\text { Chi- } \\
\text { square }\end{array}$ & Student's t & $\mathbf{p}$ & $\mathrm{Cl}$ \\
\hline Age (years)* & $23.1 \pm 4.0$ & $26.5 \pm 3.4$ & - & 3.8 & .000 & $1.6-5.2$ \\
\hline Parity* & $.5 \pm 1.1$ & $.6 \pm 1.2$ & - & .3 & .4 & $-.5-.6$ \\
\hline Gravidity* & $.8 \pm 1.5$ & $.6 \pm 1.2$ & - & .9 & .4 & $-.5-1.3$ \\
\hline Weight* & $53.5 \pm 13.0$ & $59.8 \pm 9.1$ & - & 2.3 & .02 & $.9-11.6$ \\
\hline $\mathrm{BMI}^{*}$ & $20.2 \pm 2.68$ & $22.1 \pm 2.6$ & - & 2.1 & .03 & $.08-2.6$ \\
\hline Late menarche & $15=42.9 \%$ & $5=14.3 \%$ & 5.7 & - & .01 & $8.5-48.7$ \\
\hline Duration of cycles (days)* & $28.5 \pm 2.7$ & $27.9 \pm 1.9$ & - & -1.2 & .2 & $-1.6-.5$ \\
\hline $\begin{array}{l}\text { Duration of } \\
\text { menstruations (days) }{ }^{*}\end{array}$ & $4.1 \pm 1.0$ & $3.9 \pm .7$ & - & -1.1 & .3 & $-.6-.2$ \\
\hline Habitual abortion & $4=11.4 \%$ & $4=11.4 \%$ & .1 & - & .7 & $-14.9-14.9$ \\
\hline Married & $6=17.1 \%$ & $7=20 \%$ & .000 & - & .9 & $-15.3-21.1$ \\
\hline
\end{tabular}


Beside the concentration of blood glucose that was expectedly higher in patients, it was found that late menarche was significantly more frequent in cases than in controls $(p=.01$; $\mathrm{Cl}=8.5-48)$. Comparison between cases and controls for gravidity, parity and physical variables showed no significant differences. As of menstrual troubles (Table 2), differences appeared for amenorrhea $(p=.000 ; C l=23.3-62.5)$ and spaniomenorrhea $(p=.03 ; C l=2.4-$ 43.3) that were more frequent among patients.

Table 2. Anomalies of the cycle among diabetics $(n=35)$ and non diabetics $(n=35)$

\begin{tabular}{llllll}
\hline Anomalies & Cases & Controls & Chi-square & $\mathbf{p}$ & $\mathbf{C l}$ \\
\hline Intermenstrual syndrome & $7=20 \%$ & $6=17.1 \%$ & .000 & .9 & $-15.3-21.1$ \\
Premenstrual syndrome & $16=45.7 \%$ & $13=37.1 \%$ & .2 & .6 & $-14.4-31.6$ \\
Dysmenorrhea & $17=48.6 \%$ & $23=65.7 \%$ & 1.5 & .2 & $-5.7-39.9$ \\
Amenorrhea & $19=54.3 \%$ & $4=11.4 \%$ & 12.7 & .000 & $23.3-62.5$ \\
Oligomenorrhea & $8=22.9 \%$ & $8=22.9 \%$ & .08 & .8 & $-19.7-19.7$ \\
Spaniomenorrhea & $14=40 \%$ & $6=17.1 \%$ & 3.4 & .03 & $2.4-43.3$ \\
Pollakimenorrhea & $11=31.4 \%$ & $6=17.1 \%$ & 1.2 & .3 & $-5.5-34.1$ \\
Polymenorrhea & $7=20 \%$ & $3=8.6 \%$ & 1.0 & .3 & $-4.8-27.6$ \\
Anisomenorrhea & $11=31.4 \%$ & $6=17.1 \%$ & 1.2 & .3 & $-5.5-34.1$ \\
Hypomenorrhea & $5=14.3 \%$ & $6=17.1 \%$ & .000 & 1.0 & $-14.2-19.8$ \\
Hypermenorrhea & $4=11.4 \%$ & $1=2.9 \%$ & .8 & .4 & $-3.4-20.4$ \\
Menorragia & $3=8.6 \%$ & 0 & 0 & - & - \\
Menometrorragia & $1=2.9 \%$ & 0 & 0 & - & - \\
\hline
\end{tabular}

Table 3 presents odds ratios calculation for anomalies of the cycle whose risk was at least 2 times higher in association with diabetes. Risks for amenorrhea and spaniomenorrhea were 9 and 3 times respectively higher with than without diabetes.

\section{Table 3. Influence of diabetes on cycle anomalies}

\begin{tabular}{|c|c|c|c|c|c|c|}
\hline & \multicolumn{2}{|c|}{ Study group } & \multirow[t]{2}{*}{ Total } & \multirow[t]{2}{*}{ OR } & \multicolumn{2}{|c|}{$\mathrm{Cl}$} \\
\hline Anomalies & Cases & Controls & & & & \\
\hline Amenorrhea & 19 & 4 & 23 & 9.2 & 2.7 & 31.7 \\
\hline Spaniomenorrhea & 14 & 6 & 20 & 3.2 & 1.1 & 9.8 \\
\hline Hypermenorrhea & 4 & 1 & 5 & $4.4^{*}$ & 0.5 & 41.4 \\
\hline Anisomenorrhea & 11 & 6 & 17 & $2.2^{*}$ & 0.7 & 6.9 \\
\hline Pollakimenorrhea & 11 & 6 & 17 & $2.2^{*}$ & 0.7 & 6.9 \\
\hline Polymenorrhea & 7 & 3 & 10 & $2.7^{*}$ & 0.6 & 11.3 \\
\hline
\end{tabular}

Risk for others was at least 2 times higher in patients than in controls, but might be mitigated due to confidence interval containing 1 . When age that was found significantly higher in controls was included in calculations, no significant risk for amenorrhea or spaniomenorrhea was found (OR 1.6; Cl 0.4 to 7.2 containing 1 ).

\subsection{Discussion}

Although $\mathrm{HbA} 1 \mathrm{c}$ was not available we do assume that a routine blood glucose concentration averaging $232.5 \mathrm{mg} / \mathrm{dL}$ is reflection of failure to adapt intervals of medical visits and treatment's regimens to individual needs. Medical requirements of diabetes are still out of 
reach for several diabetic individuals in low-income countries [6,7]. Resulting suboptimal management of diabetes is thus expected to increase the burden of the illness in terms of chronic complications in the community. With respect to consequences into reproductive field, less has been reported in Africa. Metabolic abnormalities that accompany poor blood glucose profile in women have proven disturbing ovulatory function [1]. In our series this can be supported by significant high frequencies of delayed menarche and lengthening of the menstrual cycle (amenorrhea and spaniomenorrhea) in diabetic women whose the majority $(71.4 \%)$ had had $\geq 3$ years of illness. Delayed menarche could be related to difficulties to control diabetes due to variable increase in need for insulin near menarche [8]. Our study registered $11 \%$ of habitual abortions. If this rate is validated due to possible misinterpretation of spaniomenorrhea it may indicate that unplanned pregnancy is likely to occur in these patients. Therefore, questionable fertility and cycle anomalies in chronically ill women, likely to be interpreted by patients themselves as inability to conceive [10-12], need to be considered as a window for a good contraception and better control of the illness, since unplanned pregnancy could result in toxic effects of hyperglycemia on the embryo. It has been largely accepted that metabolic control of diabetes is likely to minimize most of ovulatory abnormalities [1-7], although Schweiger et al. [9] found that they persisted despite improvements in diabetes management, raising the possibility that there are other factors beside glycemic control that influence menstrual regularity.

Since efforts are still needed to determine the extent of burden of diabetes, mostly in developing areas [13], the main strength of our study is that it is the first to examine menstruation in those with diabetes in sub-Saharan Africa. It shows how limited resources healthcare of diabetic women will presumably impact on their reproductive health. Small sample size is a weakness of our study. This is owed to limitations imposed by cost of dosages. Another one could be bias in self-reporting cycle disturbances due to potential memory failures of patients.

\section{CONCLUSION}

In conclusion, the issue of disturbances of reproductive function among diabetic women of our setting is to be addressed in terms of awareness to better illness management and prevention of unplanned and risky pregnancies.

\section{CONSENT}

All authors declare that written informed consent was obtained from patients and controls and from the Medical Centre of Salvation Army, Kinshasa, for publication of this study.

\section{ETHICAL APPROVAL}

This study was approved by the scientific board of the faculty of medicine (University of Kinshasa) and is scheduled to be presented in February 2013 as a fulfillment for the completion of the graduation in medicine.

\section{COMPETING INTERESTS}

The authors declare that they have no competing interests. 


\section{REFERENCES}

1. Arrais RF, Dib SA. The hypothalamus-pituitary-ovary axis and type 1 diabetes: a mini review; Hum. Reprod. 2006;21(2):327-37.

2. Gaete X, Vivanco M, Eyzaguirre FC, López P, Rhumie HK, Unanue N, Codner E. Menstrual cycle irregularities and their relationship with $\mathrm{HbA} 1 \mathrm{c}$ and insulin dose in adolescents with type 1 diabetes mellitus. Fertil Steril. 2010;94(5):1822-1826.

3. Codner E, Eyzaguirre FC, Iñiguez G, López P, Pérez-Bravo F, Torrealba IM, Cassorla F. Ovulation rate in adolescents with type 1 diabetes mellitus. Fertil Steril. 2011;95(1):197-202.

4. Codner E, Cassorla F. Puberty and ovarian function in girls with type 1 diabetes mellitus. Horm Res. 2009;71(1):12-21.

5. Dorman JS, Steenkiste AR, Foley TP, Strotmeyer ES, Burke JP, Kuller LH, et al. Menopause in type 1 diabetic women: is it premature? Diabetes. 2001;50:18571862.

6. Beran D, Yudkin JS, De Courten M. Access to care for patients with insulin-requiring diabetes in developing countries. Diabetes Care. 2005;28(9):2136-2140.

7. Smith-Spangler CM, Bhattacharya J, Goldhaber-Fiebert JD. Diabetes, Its treatment, and catastrophic medical spending in 35 developing countries. Diabetes Care. 2012;35(2):319-326.

8. Roumain JM, Charles A, De Courten MP, Hanson RL, Brodie TD, Pettitt DJ, Knowler WC. The Relationship of Menstrual Irregularity to Type 2 Diabetes in Pima Indian Women. Diabetes Care. 1998;21(3):346-49.

9. Schweiger BM, Snell-Bergeon JK, Roman R, McFann K, Klingensmith GJ. Menarche delay and irregularities persist in adolescents with type 1 diabetes. Reprod Biol Endocrinol. 2011;9(1):61-8.

10. St. James PJ, Younger MD, Hamilton BD, Waisbren SE. Unplanned pregnancies in young women with diabetes: an analysis of psychosocial factors. Diabetes Care. 1993;16(12):1572-1578.

11. Holing EV, Beyer CS, Brown ZA, Connell FA. Why don't women with diabetes plan their pregnancies? Diabetes Care. 1998;21(6):889-895.

12. Charron-Prochownik D, Sereika SM, Falsetti D, Wang SL, Becker D, Jacober S, et al. Knowledge, attitudes and behaviors related to sexuality and family planning in adolescent women with and without diabetes. Pediatr Diabetes. 2006;7(5):267-273.

13. Narayan KMV, Zhang P, Williams D, Engelgau M, Imperatore G, Kanaya A, Ramachandran A. How should developing countries manage diabetes? CMAJ. 2006; 175(7):733.doi: 10.1503/cmaj.060367.

(c) 2013 Barthélémy et al.; This is an Open Access article distributed under the terms of the Creative Commons Attribution License (http://creativecommons.org/licenses/by/3.0), which permits unrestricted use, distribution, and reproduction in any medium, provided the original work is properly cited.

Peer-review history:

The peer review history for this paper can be accessed here: http://www.sciencedomain.org/review-history.php?iid=194\&id=12\&aid=991 